\title{
Supplementation of Zebu cattle grazing Sahelian pasture - nutritional and economic aspects
}

\author{
E Schlecht 1, M Sangaré 2, K Becker ${ }^{3}$ \\ 1/nternational Livestock Research Institute, BP 12404 Niamey, Niger; 2 Station de Recherches Zootechniques du \\ Sahel, BP 12 Niono, Mali; 3inst. for Anim. Prod. in the Tropics and Subtropics (480), University of Hohenheim, \\ D-70593 Stuttgart, Germany
}

In the Sahel, supplementation of grazing cattle stabilizes livestock productivity during the dry season. To avoid waste of supplement feeds, intake from pasture vegetation and economic conditions must be considered. Feed intake was studied in Mali from 1990 to 1992. Three groups of 15 bulls and 4 oesophageally fistulated oxen each grazed natural pasture. The control group (C) relied on intake from pasture while the moderately supplemented group (M) received $1.1 \mathrm{~kg}$ day ${ }^{-1}$ of concentrate during the dry season (Nov - June) and the first month of the rainy season. The highly supplemented group $(\mathrm{H})$ received 2.4 and 1.0 $\mathrm{kg}$ day ${ }^{-1}$ of supplement feed during the dry and rainy season. Feed intake was determined from faecal excretion and digestibility of oesophageal extrusa. Body mass development was monitored, and market prices for live male cattle were collected regularly. Based on body mass changes, supplement consumption and the development of livestock and feed prices, the profitability of supplement feeding during the whole dry season and the late dry season (Feb-June), respectively, was determined by comparing gross returns and feeding costs for the different supplement treatments within and across seasons.

Related to metabolic body mass $\left(\mathrm{kg}^{0.75}\right)$, the organic matter intake (IOM) of group $C$ averaged $80 \mathrm{~g} \mathrm{day}^{-1}$ in the rainy season, and was about $10 \%$ higher in the early dry season. In the late dry season of 1991, IOM declined to $65 \mathrm{~g} \mathrm{day}^{-1}$. In the second year an average intake of $88 \mathrm{~g} \mathrm{day}^{-1}$ was observed through the whole dry season, which compared well to the intake reported for grazing Zebu cattle by Dicko et al (Nut anim II, Les bovins, in: Rapport de Rech, 5, ILCA, 96-101) and Mahler
(1991, PhD thesis, Hohenheim, Germany). At the high feeding level, $1 \mathrm{~kg} O M$ of ingested supplement replaced up to $1.4 \mathrm{OM}$ of pasture vegetation in the daily diet. On the other hand, an increase in IOM from pasture vegetation per se by up to $9 \%$ as compared to group $C$ was observed for group $M$ in 1991. However, in second year, a slight replacement effect of supplement intake on $10 \mathrm{M}$ from pasture vegetation was also observed for the moderate level of supplementation. Within two years, animals of group $\mathrm{C}, \mathrm{M}$ and $\mathrm{H}$ gained 143, 196 and $251 \mathrm{~kg}$ of liveweight. During this period, the total consumption of supplement feed amounted to 637 and $1499 \mathrm{~kg}$ OM in groups M and $\mathrm{H}$. Partial budget analysis revealed that if relatively inexpensive supplement feeds are distributed throughout the dry season, the profitability of a high level of supplementation is not greater than that of a moderate one. If the supplementation is limited to the second half of the dry season, the moderate supplementation cannot prevent slight body mass losses but is nevertheless profitable because the losses are smaller than those of unsupplemented cattle. If supplementation at a moderate level continues until the end of the first month of the rainy season, decreasing animal prices lower the revenue by more than $15 \%$ as compared to a supplementation which is stricly limited to the dry season. It was conclued that under the ecological and economical conditions prevailing in countries of the West African Sahel, moderate supplementation of grazing cattle can be profitable if it starts before considerable body mass losses occur, whereby the onset of supplement feeding is determined by the annual and regional availibility of pasture vegetation. 